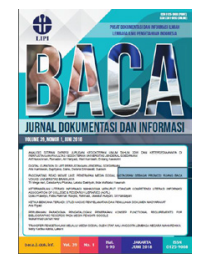

\title{
KOMPETENSI PUSTAKAWAN PERPUSTAKAAN KHUSUS: STUDI KASUS DI PERPUSTAKAAN KEMENTERIAN PENDIDIKAN DAN KEBUDAYAAN
}

\author{
Bayu Indra Saputro ${ }^{*}$, Chaidir Amir ${ }^{2}$ \\ ${ }^{1}$ Balai Arkeologi Daerah Istimewa Yogyakarta, Kemendikbud RI \\ ${ }^{2}$ Biro Komunikasi dan Layanan Masyarakat, Kemendikbud RI \\ *Korespondensi: bayu.indra@kemdikbud.go.id
}

Diajukan: 06-08-2018; Direview: 05-09-2018; Diterima: 18-09-2018; Direvisi: 12-11-2108

\begin{abstract}
Increasing competency of librarians in Kemendikbud is essential to support the vision and mission of there. Special libraries must be there professional, semi-professional, and non-professional personnel according to the National Standard of Special Library. This study examines the composition of librarians in Kemendikbud, both from the composition of position, age, and education with qualitative descriptive method. Collecting data by purposive technique. Of the respondents who manage the special library Kemendikbud as many as 136 people, only 21 people $(15,44 \%)$ who occupy functional positions librarian. While the composition of expert librarians, skill librarians and administrative personal in Kemendikbud is 18:3:115. Composition of librarian age $46-50$ years $(28,57 \%), 51-55$ as many as 4 people $(19,05 \%), 56-60$ as many as 4 people (19,05\%), 36-40 as many as 3 people (14,29\%), 25-30 as many as 2 people $(9,52 \%)$, and $41-45$ as many as 2 people $(9,52 \%)$. Librarians in Kemendikbud scope mostly have S1 degree as much as $15(71,42 \%)$, S2, and D3 respectively amounted to 3 people $(14,29 \%)$. Most of the librarians have educational background of the library $(61,90 \%)$, education $(19,05 \%)$, literature $(14,29 \%)$, and state administration $(4,76 \%)$.
\end{abstract}

\begin{abstract}
ABSTRAK
Peningkatan kompetensi pustakawan di Kemendikbud sangat penting untuk mendukung visi dan misi lembaga. Perpustakaan khusus harus memiliki kepala perpustakaan, pustakawan, dan tenaga teknis agar sesuai Standar Nasional Perpustakaan Khusus. Penelitian ini mengkaji komposisi pustakawan, baik komposisi jabatan, usia, maupun pendidikan, dengan metode deskriptif kualitatif. Pengumpulan data menggunakan teknik purposif. Hasil penelitian menunjukkan bahwa pengelola Perpustakaan Kemendikbud ada 136 orang, dan hanya 21 orang $(15,44 \%)$ yang menduduki jabatan fungsional pustakawan. Komposisi pustakawan ahli, pustakawan terampil, dan tenaga teknis perpustakaan di Kemendikbud adalah 18:3:115. Komposisi usia pustakawan 46-50 tahun sejumlah (28,57\%), 51-55 sejumlah 4 orang (19,05\%), 56-60 sejumlah 4 orang (19,05\%), 36-40 sejumlah 3 orang $(14,29 \%), 25-30$ sejumlah 2 orang $(9,52 \%)$, dan $41-45$ sejumlah 2 orang $(9,52 \%)$. Pustakawan Kemendikbud sebagian besar berpendidikan S1 sejumlah 15 (71,42\%), S2, dan D3 masing-masing berjumlah 3 orang $(14,29 \%)$. Sebagian besar pustakawan berlatar belakang pendidikan ilmu perpustakaan $(61,90 \%)$, pendidikan $(9,05 \%)$, sastra $(14,29 \%)$, dan administrasi negara $(4,76 \%)$.
\end{abstract}

Keywords: Librarian; Competency; Human resources; User profile; Special library

\section{PENDAHULUAN}

Perpustakaan berkembang pesat seiring dengan perkembangan kehidupan masyarakat, kebutuhan akan pengetahuan, dan perkembangan teknologi informasi. Hal tersebut membawa dampak pengelompokan berbagai jenis perpustakaan yang ada di masyarakat (Rufaidah, 2009). Saputro (2012) mengatakan perpustakaan muncul karena kebutuhan bagi pencari informasi terhadap bank data yang berperan dalam penyimpanan informasi yang dapat ditelusur kembali informasinya. Begitu halnya dengan perpustakaan khusus, yang berkembang karena tuntutan kebutuhan informasi lembaga induknya. 
Menurut UU No.43 tahun 2007 tentang Perpustakaan, perpustakaan khusus diperuntukan secara terbatas bagi pemustaka di lingkungan lembaga pemerintah, lembaga masyarakat, lembaga pendidikan keagamaan, rumah ibadah atau organisasi lainnya. Karakteristik perpustakaan khusus pada lingkup layanannya yang terbatas pada kelompok tertentu, dan subjek terbatas pada fungsi lembaga induk (Totterdell, 2000). Surachman (2005) mengatakan perpustakaan khusus didirikan untuk mendukung visi dan misi lembaga tertentu yang berfungsi sebagai pusat informasi terutama berhubungan dengan penelitian dan pengembangan lembaga. Biasanya perpustakaan khusus berada di bawah badan, institusi, lembaga ilmiah, organisasi bisnis, departemen atau nondepartemen. Perpustakaan khusus ini misalnya Perpustakaan BKKBN, Perpustakaan PDII-LIPI, Perpustakaan PT.Semen Gresik, Perpustakaan Lembaga Administrasi Negara, Perpustakaan Rumah Sakit Pertamina, dan Perpustakaan Kementerian Pendidikan dan Kebudayaan (Kemendikbud).

Perpustakaan Kemendikbud merupakan perpustakaan khusus yang bertugas melaksanakan pengelolaan perpustakaan dan penyebaran informasi dari hasil kajian bidang pendidikan, kebudayaan, bahasa, sastra, sejarah, arkeologi, seni, film, dan teknologi pendidikan pada masing-masing satuan kerja. Pembinaan perpustakaan khusus di Kemendikbud dilaksanakan oleh Biro Komunikasi dan Layanan Masyarakat, berdasarkan Peraturan Mendikbud RI No.11 tahun 2015 tentang Organisasi dan Tata Kerja Kementerian Pendidikan dan Kebudayaan.

Perpustakaan Kemendikbud berperan penting dalam menunjang penyebarluasan hasil-hasil penelitian dan kajian bidang pendidikan dan kebudayaan. Peran perpustakaan tersebut mendorong perlunya tenaga profesional, baik tenaga fungsional pustakawan maupun tenaga teknis perpustakaan. Kebutuhan tenaga perpustakaan tersebut tergantung dari beban kerja atau tugas pokok dan fungsi yang diemban oleh masing-masing satuan kerja di Kemendikbud. Perpustakaan khusus di lembaga penelitian sebenarnya berperan penting dalam menunjang keberhasilan penelitian dan pengembangan teknologi baru di lembaga masing-masing. Perpustakaan ini juga menunjang keberhasilan output kegiatan dari pelaku penelitian dan pengembangan, salah satunya adalah karya tulis ilmiah (Masiani 2015).

Pentingnya analisis kebutuhan tenaga pustakawan dan tenaga teknis perpustakaan di Kemendikbud ini menjadi dasar kajian penelitian. Tujuan penelitian ini adalah untuk mengetahui komposisi pengelola perpustakaan khusus, tenaga perpustakaan (pustakawan dan tenaga teknis), usia, dan pendidikan tenaga perpustakaan. Kajian ini diharapkan bermanfaat bagi pimpinan Perpustakaan Kemendikbud khususnya sebagai bahan pertimbangan atau kebijakan dalam pembinaan sumber daya manusia atau tenaga perpustakaan.

\section{TINJAUAN PUSTAKA}

\subsection{Perpustakaan Khusus}

Sulistyo-Basuki (1991) mengatakan ada beberapa karakteristik perpustakaan khusus, yaitu: (1) menyediakan informasi bagi staf badan induknya guna mendukung tercapainya visi dan misi lembaga; (2) bernaung pada lembaga induk, seperti lembaga profesi, perusahaan, departemen dan non-departemen, rumah sakit, badan peradilan, pemerintah daerah yang tidak mencari keuntungan; (3) memberikan jasanya pada pemakai tertentu saja; (4) subjek koleksi terbatas pada disiplin ilmu tertentu; (5) titik berat koleksi bukan pada buku melainkan jurnal ilmiah, prosiding, laporan penelitian yang bersifat mutakhir; (6) memiliki sedikit staf; dan (7) peran pustakawan melakukan penelitian - untuk mengetahui kebutuhan referensi dan mendukung tugas anggota di lembaganya. Sedangkan fungsi perpustakaan khusus adalah sebagai pusat 
dokumentasi dan penyedia rujukan penelitian yang dilakukan oleh lembaga induk untuk mendukung kelancaran tugas pokok lembaga (Ria, 2017).

Menurut Peraturan Kepala Perpustakaan Nasional RI No.14 tahun 2017 tentang Standar Nasional Perpustakaan, tujuan perpustakaan khusus, yaitu: (a) menunjang program lembaga induk; (b) menunjang penelitian lembaga induk; (c) menggalakkan minat baca di satuan kerja lembaga induk; dan (d) memenuhi kebutuhan pemustaka di lingkungan perpustakaan. Adapun tugasnya yaitu melayani pemustaka dengan menyediakan bahan perpustakaan/bacaan yang sesuai dengan kebutuhan lembaga induk dan masyarakat di sekitarnya; dan fungsinya yaitu sebagai perpustakaan rujukan, pusat deposit, dan pusat sumber belajar masyarakat di lingkungan lembaga induk. Adapun struktur organisasi perpustakaan khusus, secara umum terdiri dari Kepala Perpustakaan, Pelayanan Teknis, dan Pelayanan Pustaka (Gambar 1).

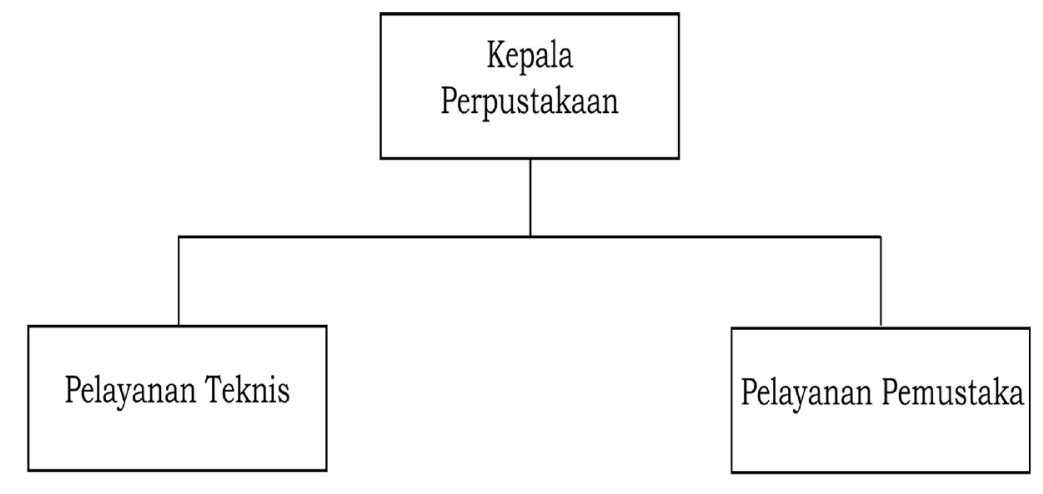

Gambar 1. Struktur organisasi perpustakaan khusus (Perpusnas RI, 2017)

\subsection{Tenaga Perpustakaan Khusus}

Perpustakaan tidak akan berfungsi secara maksimal tanpa adanya sumber daya manusia yang profesional dalam menjalankan organisasi perpustakaan. Oleh karena itu, setiap perpustakaan memiliki tenaga profesional, yaitu pustakawan dan tenaga non-profesional (tenaga administrasi atau teknis) yang bekerja secara profesional dalam penyebarluasan informasi dan pelayanan maksimal kepada pemustaka (Suwarno, 2009). Pustakawan sebagai ujung tombak dalam penyebarluasan informasi di perpustakaan dituntut untuk meningkatkan kinerjanya secara profesional.

Menurut UU No.43 tahun 2007 tentang perpustakaan, pustakawan adalah seseorang yang memiliki kompetensi yang diperoleh melalui pendidikan dan/atau pelatihan kepustakawanan, serta mempunyai tugas dan tanggung jawab dalam melaksanakan pengelolaan dan pelayanan kepada pemustaka. Suwarno (2009) mendefinisikan pustakawan sebagai tenaga kerja bidang perpustakaan yang telah memiliki ilmu pendidikan perpustakaan, baik pelatihan, kursus, seminar dan formal. Pendidikan bidang perpustakaan inilah yang nantinya membentuk pustakawan yang profesional dalam pengelolaan dan pelayanan kepada pemustaka.

Menurut Peraturan Kepala Perpustakaan Nasional RI No.14 tahun 2017 tentang Standar Nasional Perpustakaan, tenaga perpustakaan khusus memiliki tenaga paling sedikit tiga orang, yaitu 1 orang kepala perpustakaan, 1 orang pustakawan, dan 1 orang tenaga teknis. Kualifikasi Kepala Perpustakaan paling rendah berlatar belakang pendidikan sarjana (S-1) ilmu perpustakaan atau bidang ilmu lain yang ditambah diklat perpustakaan. Sedangkan kualifikasi pustakawan yaitu berpendidikan diploma dua (D2) atau diploma tiga (D3) dan sarjana bidang ilmu perpustakaan atau sarjana bidang lain yang telah mengikuti pendidikan dan pelatihan Calon Pustakawan Tingkat Ahli (CPTA) atau Calon Pustakawan Tingkat Terampil (CPTT). 
Tenaga tersebut diberi tugas, tanggung jawab, wewenang, dan hak secara penuh oleh pejabat yang berwenang untuk melakukan kegiatan kepustakawanan. Adapun kualifikasi tenaga teknis perpustakaan, yaitu pegawai yang berpendidikan paling rendah diploma non-ilmu perpustakaan dan informasi yang secara teknis mendukung pelaksanaan fungsi perpustakaan. Tenaga tersebut diberi tugas, tanggung jawab, wewenang, dan hak secara penuh oleh pejabat yang berwenang untuk melakukan penunjang kegiatan perpustakaan.

\subsection{Kompetensi Pustakawan}

Nashihuddin (2015) mengatakan bahwa pustakawan sebagai suatu profesi sebaiknya memiliki kompetensi. Kompetensi adalah kemampuan seseorang yang mencakup pengetahuan, keterampilan yang dimiliki, dan sikap kerja yang dapat dilihat kemampuannya dalam menyelesaikan suatu pekerjaan sesuai dengan standar kinerja yang ditentukan (Winarko, 2017). Kompetensi dibedakan menjadi kompetensi umum, kompetensi inti, dan kompetensi khusus.

- Kompetensi umum, merupakan kompetensi dasar yang wajib dimiliki oleh pustakawan, seperti kemampuan mengoperasikan komputer tingkat dasar, menyusun rencana kerja, dan menyusun laporan kinerja perpustakaan.

- Kompetensi inti, merupakan kompetensi yang harus dimiliki pustakawan, seperti pengadaan bahan pustaka, pengkatalogisasian, layanan sirkulasi, penelusuran informasi, promosi perpustakaan, dan literasi informasi.

- Kompetensi khusus, bersifat spesifik, seperti membuat literatur sekunder, melakukan kajian perpustakaan, dan menyusun karya tulis ilmiah.

Murphy (1991) menjelaskan kompetensi pustakawan di perpustakaan khusus sebagai suatu kompetensi khusus. Kompetensi khusus ini unik dan saling mempengaruhi satu sama lain, yaitu pengetahuan, pemahaman, keahlian, dan perilaku. Kompetensi unik dan khusus termasuk di dalamnya dalam penguasaan secara mendalam berbagai informasi khusus sesuai subjek spesialis, berbagai informasi atau pengetahuan yang dapat mempertemukan pengguna dengan informasi yang dibutuhkan.

\section{METODE}

Penelitian ini menggunakan metode deskripif kualitatif. Penelitian deskriptif kualitatif menggambarkan kondisi sumber daya manusia yang ada di Perpustakaan Kemendikbud (Ali, 2006). Pengumpulan data dengan teknik purposive sampling (sampel bertujuan), yang bertujuan untuk memperoleh informasi secara selektif, cermat, sampel terbaik yang dapat mewakili keseluruhan populasi (Ratna, 2010). Sugiyono (2009) mengatakan bahwa sampel adalah sebagian dari jumah dan karakteristik yang dimiliki oleh populasi tersebut. Populasi penelitian ini adalah seluruh pengelola perpustakaan khusus, baik pustakawan, pengolah bahan pustaka, petugas perpustakaan, pegawai dengan jabatan lain. serta tenaga honorer yang ditugaskan di 172 perpustakaan di Kemendikbud (Tabel 1).

Tabel 1. Data Perpustakaan Khusus di Lingkungan Kemendikbud

\begin{tabular}{|c|l|c|}
\hline No. & \multicolumn{1}{|c|}{ Satuan Kerja } & Jumlah \\
\hline 1 & Sekretariat Jenderal & 13 \\
\hline 2 & Inspektorat Jenderal & 1 \\
\hline 3 & Direktorat Jenderal Guru dan Tenaga Kependidikan & 15 \\
\hline 4 & $\begin{array}{l}\text { Direktorat Jenderal Pendidikan Anak Usia Dini dan } \\
\text { Pendidikan Masyarakat }\end{array}$ & 30 \\
\hline 5 & Direktorat Jenderal Pendidikan Dasar dan Menengah & 35 \\
\hline
\end{tabular}




\begin{tabular}{|c|l|c|}
\hline 6 & Direktorat Jenderal Kebudayaan & 34 \\
\hline 7 & Badan Pengembangan dan Pembinaan Bahasa & 31 \\
\hline 8 & Badan Penelitian dan Pengembangan & 13 \\
\hline \multicolumn{2}{|c|}{ Total } & $\mathbf{1 7 2}$ \\
\hline
\end{tabular}

Data penelitian ini bersumber dari angket/kuesioner (Google Form) yang disebarkan kepada seluruh pengelola perpustakaan khusus di lingkungan Kemendikbud. Angket disebarkan dari Januari sampai Februari 2018 dalam bentuk bentuk pertanyaan terbuka. Isi angket berupa data responden, seperti data nama, NIP, tempat dan tanggal lahir, nama instansi; dan data pertanyaan pilihan berganda - untuk pertanyaan jabatan pengelola perpustakaan. Dari penyebaran angket diketahui 136 pengelola perpustakaan dari 69 satuan kerja yang mengisi data diri. Data tersebut kemudian dianalisis dan disajikan dalam bentuk deskripstif, dan selanjutnya menjadi bahan kesimpulan penelitian.

\section{HASIL DAN PEMBAHASAN}

\subsection{Pengelola Perpustakaan Kemdikbud}

Dari 136 responden yang mengisi data diri di angtek diketahui bahwa pengelola Perpustakaan Kemdikbud terbanyak berasal dari Direktorat Jenderal Guru dan Tenaga Kependidikan (Ditjen GTK), yakni 30 orang (22\%), sedangkan yang paling sedikit berasal dari Inspektorat Jenderal (Itjen), yakni 1 orang (1\%). (Tabel 2).

Tabel 2. Responden Data Penelitian

\begin{tabular}{|c|l|c|c|}
\hline No. & \multicolumn{1}{|c|}{ Satuan Kerja } & Jumlah & $\begin{array}{c}\text { Persentase } \\
(\mathbf{\%})\end{array}$ \\
\hline 1 & Setjen & 18 & 13 \\
\hline 2 & Itjen & 1 & 1 \\
\hline 3 & Ditjen GTK & 30 & 22 \\
\hline 4 & Ditjen PAUD Dikmas & 4 & 3 \\
\hline 5 & Ditjen Dikdasmen & 25 & 18 \\
\hline 6 & Ditjen Kebudayaan & 25 & 18 \\
\hline 7 & Badan Bahasa & 24 & 18 \\
\hline 8 & Balitbang & 9 & 7 \\
\hline \multicolumn{2}{r|}{ Total } & $\mathbf{1 3 6}$ & $\mathbf{1 0 0}$ \\
\hline
\end{tabular}

Dilihat dari jabatan pengelola perpustakaan, diketahui dari 136 pengelola perpustakaan terdiri dari 21 orang $(15,44 \%)$ jabatan fungsional pustakawan (ahli dan terampil); 114 orang $(83,82 \%)$ jabatan funsional umum (pengolahan bahan pustaka, petugas perpustakaan, dan jabatan lainnya); dan 1 orang $(0,74 \%)$ jabatan struktural (Tabel 3).

Tabel 3. Jabatan Pengelola Perpustakaan Kemendikbud

\begin{tabular}{|c|c|c|c|c|}
\hline No. & Jabatan & Jenjang & Jumlah & $\begin{array}{c}\text { Persentase } \\
(\%)\end{array}$ \\
\hline \multirow[t]{5}{*}{1} & \multirow{5}{*}{$\begin{array}{l}\text { Jabatan } \\
\text { Fungsional } \\
\text { Tertentu (JFT) }\end{array}$} & Pustakawan Ahli Madya & 4 & 2,99 \\
\hline & & Pustakawan Ahli Muda & 9 & 6,62 \\
\hline & & Pustakawan Ahli Pertama & 5 & 3,68 \\
\hline & & $\begin{array}{l}\text { Pustakawan Terampil } \\
\text { Penyelia }\end{array}$ & 2 & 1,47 \\
\hline & & Pustakawan Terampil & 1 & 0,74 \\
\hline
\end{tabular}




\begin{tabular}{|c|c|c|c|c|}
\hline & & Pelaksana & & \\
\hline \multirow[t]{3}{*}{2} & \multirow{3}{*}{$\begin{array}{l}\text { Jabatan } \\
\text { Fungsional } \\
\text { Umum (JFU) }\end{array}$} & Pengolah Bahan Pustaka & 6 & 4,41 \\
\hline & & Petugas Perpustakaan & 86 & 63,24 \\
\hline & & Jabatan Lainnya & 22 & 16,18 \\
\hline 3 & $\begin{array}{l}\text { Jabatan } \\
\text { Struktural }\end{array}$ & Struktural & 1 & 0,74 \\
\hline
\end{tabular}

Berdasarkan standar nasional perpustakaan khusus diketahui bahwa komposisi pengelola perpustakaan khusus adalah Kepala Perpustakaan : Pustakawan : Tenaga Teknis $=1: 1: 1$ (Perpusnas, 2017). Saat ini komposisi pengelola Perpustakaan Kemendikbud adalah 1: 21 : 114, jabatan struktural hanya ada di Biro Komunikasi dan Layanan Masyarakat; sedangkan di satuan kerja lainnya tidak terdapat jabatan struktural kepala perpustakaan. Di satuan kerja hanya ada pengelola perpustakaan dengan jabatan pustakawan sejumlah 21 orang dan tenaga teknis sejumlah 114 orang. Dapat dikatakan bahwa pustakawan yang bekerja di Perpustakaan Kemendikbud jumlahnya sangat minim. Sementara itu, tenaga teknis yang bekerja sebagai pengelola perpustakaan, terbagi menjadi pengolah bahan pustaka (6 orang), petugas perpustakaan (86 orang), dan jabatan lainnya (honorer, pengkaji kebahasaan, pengolah data ketatalaksanaan, pengadministrasi persuratan, dan BMN).

Minimnya tenaga perpustakaan yang profesional di Kemendikbud perlu menjadi perhatian para pemangku kebijakan khususnya dalam hal pengembangan profesi pustakawan di Kemendikbud. Tugas yang diemban pustakawan di Kemendikbud sangat berat, yakni mengelola perpustakaan, menyebarkan, dan mendiseminasikan hasil kajian pendidikan dan kebudayaan kepada masyarakat. Hal ini seiring dengan tugas lembaga pemerintah, khususnya lembaga penelitian yang diharapkan dapat mempublikasikan hasil penelitian, baik melalui media cetak maupun online.

\subsection{Komposisi Pustakawan Kemendikbud}

Sumber daya manusia di Perpustakaan Kemendikbud terdiri dari pustakawan, pengolahan bahan pustaka, petugas perpustakaan, dan jabatan lainnya. Dibandingkan dengan jumlah sumber daya struktural dan administrasi, jumlah pustakawan di Kemendikbud hanya 15,44\% dari jumlah keseluruhan pengelola perpustakaan. Komposisi jumlah pustakawan di Kemendikbud didominasi oleh pustakawan muda, 9 orang $(6,62 \%)$; pustakawan pertama, 5 orang (3,68\%); pustakawan madya, 4 orang (2,94\%); pustakawan penyelia, 2 orang $(1,47 \%)$; dan pustakawan pelaksana, 1 orang $(0,74 \%)$.

Jumlah pustakawan di Kemendikbud yang paling banyak berasal dari Dirjen Guru dan Tenaga Kependidikan (6 orang); Badan Pengembangan dan Pembinaan Bahasa (5 orang); Sekretariat Jenderal (4 orang); Dirjen Pendidikan Dasar dan Menengah (4 orang); dan Dirjen Kebudayaan (1 orang). Sedangkan Dirjen Pendidikan Anak Usia Dini dan Pendidikan Masyarakat serta Badan Penelitian dan Pengembangan tidak memili pustakawan (Tabel 4).

Tabel 4. Sebaran Jumlah Pustakawan di Kemendikbud

\begin{tabular}{|c|l|c|c|c|c|c|c|c|}
\hline \multirow{2}{*}{ No. } & \multirow{2}{*}{ Satuan Kerja } & \multicolumn{7}{c|}{ Pustakawan } \\
\cline { 3 - 9 } & & Pelaksana & $\begin{array}{c}\text { Pelaksana } \\
\text { Lanjutan }\end{array}$ & Penyelia & Pertama & Muda & Madya & Utama \\
\hline 1 & Sekretariat Jenderal & 1 & - & - & 3 & 1 & - & - \\
\hline 2 & Inspektorat Jenderal & - & - & - & - & - & - & - \\
\hline 3 & Direktorat Jenderal Guru dan & - & - & 1 & 1 & 3 & 1 & - \\
\hline
\end{tabular}




\begin{tabular}{|c|l|c|c|c|c|c|c|c|}
\hline & Tenaga Kependidikan & & & & & & & \\
\hline 4 & $\begin{array}{l}\text { Direktorat Jenderal Pendidikan } \\
\text { Anak Usia Dini dan Pendidikan } \\
\text { Masyarakat }\end{array}$ & - & - & - & - & - & - & - \\
\hline 5 & $\begin{array}{l}\text { Direktorat Jenderal Pendidikan } \\
\text { Dasar dan Menengah }\end{array}$ & - & - & - & - & 3 & 1 & - \\
\hline 6 & Direktorat Jenderal Kebudayaan & - & - & - & - & 1 & - & - \\
\hline 7 & $\begin{array}{l}\text { Badan Pengembangan dan } \\
\text { Pembinaan Bahasa }\end{array}$ & - & - & 1 & 1 & 1 & 2 & - \\
\hline 8 & $\begin{array}{l}\text { Badan Penelitian dan } \\
\text { Pengembangan }\end{array}$ & - & - & - & - & - & - & - \\
\hline
\end{tabular}

Menurut Rufaidah (2009), Standar Nasional Perpustakaan Khusus menyebutkan bahwa komposisi pustakawan pada perpustakaan khusus adalah Pustakawan Ahli:Pustakawan Terampil:Tenaga Teknis adalah 1:2:4. Saat ini komposisi pengelola perpustakaan Kemendikbud adalah 18:3:114 atau 6:1:38, yang berarti bahwa komposisi tenaga perpustakaan Kemendikbud belum ideal. Jumlah tenaga profesional pustakawan madya lebih besar dari pada jumlah pustakawan terampil. Selain itu, jumlah tenaga teknis perpustakaan (non-profesional) lebih besar jika dilihat dari komposisi standar pengelola perpustakaan khusus. Hal tersebut disebabkan sebagian pegawai (calon pustakawan) masih menunggu pengangkatan jabatan fungsional, dan adanya pegawai honorer yang bekerja di perpustakaan-karena beberapa satker masih kekurangan tenaga perpustakaan. Sebagai solusi, perpustakaan perlu menambah peta jabatan pustakawan pada setiap satuan kerja di lingkungan Kemendikbud, baik pustakawan terampil maupun pustakawan ahli. Selain itu, BKLM perlu membentuk tim penilai jabatan fungsional pustakawan agar penilaian angka kredit yang diajukan calon pustakawan dan pustakawan (ke jenjang yang lebih tinggi) dapat terlayani secara maksimal.

\subsection{Komposisi Kelompok Usia Pustakawan Kemendikbud}

Berdasarkan komposisi usia pustakawan terlihat bahwa usia termuda pustakawan di Kemendikbud adalah 27 tahun dan tertua adalah 60 tahun. Menurut kelompok usia, pustakawan Kemendikbud didominasi oleh kelompok usia 46-50 tahun, 6 orang (28,57\%); usia 51-55, 4 orang $(19,05 \%)$; usia 56-60, 4 orang $(19,05 \%)$; usia $36-40,3$ orang $(14,29 \%)$; usia $25-30,2$ orang $(9,52 \%)$; dan usia 41-45, 2 orang (9,52\%) (Tabel 5).

Tabel 5. Komposisi Usia Pustakawan Kemendikbud

\begin{tabular}{|c|c|c|}
\hline $\begin{array}{c}\text { Usia } \\
\text { (tahun) }\end{array}$ & $\begin{array}{c}\text { Jumlah } \\
\text { (orang) }\end{array}$ & $\begin{array}{c}\text { Persentase } \\
(\mathbf{\%})\end{array}$ \\
\hline $25-30$ & 2 & 9,52 \\
\hline $30-35$ & 0 & 0 \\
\hline $36-40$ & 3 & 14,29 \\
\hline $41-45$ & 2 & 9,52 \\
\hline $46-50$ & 6 & 28,57 \\
\hline $51-55$ & 4 & 19,05 \\
\hline $56-60$ & 4 & 19,05 \\
\hline$>60$ & 0 & 0 \\
\hline Total & $\mathbf{2 1}$ & $\mathbf{1 0 0}$ \\
\hline
\end{tabular}


Kondisi ini perlu mendapatkan perhatian dari pembuat kebijakan karena beberapa pustakawan dalam kurun waktu 2018 - 2021 akan memasuki usia pensiun. Pengangkatan pustakawan dalam beberapa tahun terakhir hanya berjumlah 4 orang. Hal tersebut disebabkan masih belum adanya formasi jabatan pustakawan di setiap satuan kerja Kemendikbud, sehingga calon pustakawan belum dapat mengajukkan jabatan fungsional pustakawan walaupun sudah menyusun DUPAK atau PAK Pustakawan dari Perpustakaan Daerah.

Sebenarnya tenaga teknis perpustakaan yang berjumlah 114 orang $(83,82 \%)$, memiliki banyak potensi untuk dikembangkan menjadi tenaga pustakawan. Pada Tabel 6 terlihat bahwa mereka ada 77 orang yang sudah berusia 25 - 50 tahun memiliki kemungkinan untuk diangkat menjadi tenaga pustakawan, baik pustakawan tingkat terampil maupun pustakawan tingkat ahli. Hal tersebut sesuai dengan pengangkatan jabatan fungsional pertama kali berusia paling tinggi 53 tahun yang diatur dalam Peraturan Menteri Pendayagunaan Aparatur Negara dan Reformasi Birokrasi RI No.9 Tahun 2014 tentang Jabatan Fungsional Pustakawan dan Angka Kreditnya.

Tabel 6 Komposisi Usia Tenaga Teknis Perpustakaan Kemendikbud

\begin{tabular}{|c|c|c|}
\hline $\begin{array}{c}\text { Usia } \\
\text { (tahun) }\end{array}$ & $\begin{array}{c}\text { Jumlah } \\
\text { (orang) }\end{array}$ & $\begin{array}{c}\text { Persentase } \\
(\mathbf{\%})\end{array}$ \\
\hline $25-30$ & 8 & 7,02 \\
\hline $30-35$ & 15 & 13,16 \\
\hline $36-40$ & 19 & 16,67 \\
\hline $41-45$ & 19 & 16,67 \\
\hline $46-50$ & 16 & 14,04 \\
\hline $51-55$ & 22 & 19,30 \\
\hline $56-60$ & 15 & 13,16 \\
\hline$>60$ & 0 & 0 \\
\hline Total & $\mathbf{1 1 4}$ & $\mathbf{1 0 0}$ \\
\hline
\end{tabular}

\subsection{Komposisi Pendidikan Pustakawan Kemendikbud}

Berdasarkan komposisi pendidikan pustakawan di Kemendikbud diketahui bahwa sebagian besar berpendidikan S1, berjumlah 15 orang (71,42\%), S2 dan D3 masing-masing berjumlah 3 orang $(14,29 \%)$ (Tabel 7).

Tabel 7. Komposisi Pendidikan Pustakawan Kemendikbud

\begin{tabular}{|c|c|c|}
\hline Pendidikan & $\begin{array}{c}\text { Jumlah } \\
\text { (orang) }\end{array}$ & $\begin{array}{c}\text { Persentase } \\
(\%)\end{array}$ \\
\hline D3 & 3 & 14,29 \\
\hline S1 & 15 & 71,42 \\
\hline S2 & 3 & 14,29 \\
\hline Total & $\mathbf{2 1}$ & $\mathbf{1 0 0}$ \\
\hline
\end{tabular}

Dilihat dari latar belakang pendidikan pustakawan, terlihat bahwa sebagian besar pustakawan berlatar belakang pendidikan Ilmu Perpustakaan (61,90\%), Pendidikan (19,05\%), Sastra (14,29\%), dan Administrasi Negara (4,76\%) (Tabel 8). 
Tabel 8 Latar Belakang Bidang Ilmu Pustakawan Kemendikbud

\begin{tabular}{|c|c|c|}
\hline Bidang Ilmu & $\begin{array}{l}\text { Jumlah } \\
\text { (orang) }\end{array}$ & $\begin{array}{c}\text { Persentase } \\
(\%)\end{array}$ \\
\hline Perpustakaan & 13 & 61,90 \\
\hline Pendidikan & 4 & 19,05 \\
\hline Sastra & 3 & 14,29 \\
\hline Administrasi Negara & 1 & 4,76 \\
\hline Total & 21 & 100 \\
\hline
\end{tabular}

Dilihat dari latar pendidikan tenaga teknis perpustakaan di Kemendikbud diketahui bahwa mereka yang berlatar pendidikan S1 ada 53 orang $(46,48 \%)$; D3 sejumlah 12 orang $(10,53 \%)$; S2 sejumlah 11 orang $(9,65 \%)$; dan D1 sejumlah 1 orang $(0,88 \%)$ (Tabel 9).

Tabel 9. Latar Belakang Pendidikan Tenaga Teknis Perpustakaan Kemendikbud

\begin{tabular}{|c|c|c|}
\hline Pendidikan & $\begin{array}{c}\text { Jumlah } \\
\text { (orang) }\end{array}$ & $\begin{array}{c}\text { Persentase } \\
(\mathbf{\%})\end{array}$ \\
\hline SMA & 37 & 32,46 \\
\hline D1 & 1 & 0,88 \\
\hline D3 & 12 & 10,53 \\
\hline S1 & 53 & 46,48 \\
\hline S2 & 11 & 9,65 \\
\hline Total & $\mathbf{1 1 4}$ & $\mathbf{1 0 0}$ \\
\hline
\end{tabular}

Dilihat dari bidang ilmunya, diketahui bahwa tenaga teknis perpustakaan Kemendikbud sebagian besar lulusan dari Ilmu Perpustakaan (40,26\%); Ekonomi/Administrasi/Manajemen (15,58\%); Sastra (14,29\%); Arkeologi/Antropologi, Komunikasi/Informatika Grafis dan Pendidikan (masing-masing 7,79\%); Bimbingan Konseling (2,60\%); dan Geografi 1,30\% (Tabel 10).

Tabel 10. Bidang Ilmu Tenaga Adminstrasi Perpustakaan Kemendikbud

\begin{tabular}{|l|c|c|}
\hline \multicolumn{1}{|c|}{ Bidang Ilmu } & $\begin{array}{c}\text { Jumlah } \\
\text { (orang) }\end{array}$ & $\begin{array}{c}\text { Persentase } \\
(\mathbf{\%})\end{array}$ \\
\hline Perpustakaan & 31 & 40,26 \\
\hline Sastra & 11 & 14,29 \\
\hline Bimbingan Konseling & 2 & 2,60 \\
\hline $\begin{array}{l}\text { Ekonomi/Administrasi/ } \\
\text { Manajemen }\end{array}$ & 12 & 15,58 \\
\hline Arkeologi/Antropologi & 6 & 7,79 \\
\hline $\begin{array}{l}\text { Komunikasi/Informatika/ } \\
\text { Grafis }\end{array}$ & 6 & 7,79 \\
\hline Teknik Total & 2 & 2,60 \\
\hline Pendidikan & 6 & 7,79 \\
\hline Geografi & 77 & 1,30 \\
\hline \multicolumn{1}{|c|}{} & 100 \\
\hline
\end{tabular}

Tenaga teknis perpustakaan yang berlatar pendidikan Ilmu Perpustakaan (31 orang) dapat mengajukan jabatan fungsional pustakawan (DUPAK Pustakawan) melalui penilaian ke perpustakaan daerah di setiap satuan kerjanya, dengan komposisi penilaian $80 \%$ kegiatan 
wajib dan 20\% kegiatan penunjang. Sedangkan tenaga teknis perpustakaan dengan bidang ilmu lain, harus mengikuti diklat alih jalur yang diselenggarakan oleh Perpustakaan Nasional RI. Setelah mendapatkan sertifikat alih jalur, kemudian mengajuan DUPAK Pustakawan. Dalam proses pengajuannya, mereka harus menunggu peta jabatan fungsional pustakawan di setiap satuan kerjanya.

\subsection{Pengembangan Karir Pengelola Perpustakaan Kemendikbud}

Pembinaan karir pustakawan sebagai Aparatur Sipil Negara (ASN) menjadi modal dasar pembentukan tenaga profesional dengan mengutamakan keahlian-sesuai kode etik dan peraturan perundang-undangan sebagimana yang diatur dalam UU RI No.5 tahun 2014 tentang Aparatur Sipil Negara. Sulistyowati (2012) mengatakan pengembangan karir pustakawan dapat dilakukan melalui kegiatan: (1) pendidikan formal melalui program diploma, sarjana, megister atau doktor dalam ilmu perpustakaan, dokumentasi, dan informasi; (2) pendidikan dan pelatihan bidang perpustakaan, dokumentasi; (3) seminar, lokakarya, workshop, konferensi, simposium, diskusi panel, dan pertemuan ilmiah lainnya; (4) lomba-lomba di bidang perpustakaan; (5) mengikuti salah satu organisasi atau kelembagaan bidang perpustakaan, seperti Ikatan Pustakawan Pustakawan/IPI; (6) meningkatkan keahlian terutama bidang komputer dan bahasa Inggris; (7) mengikuti perkembangan teknologi informasi dan komunikasi; (8) melakukan studi banding dan peninjauan ke perpustakaan yang sudah maju; (9) meningkatkan semangat dan motivasi kerja untuk memberikan pelayanan yang terbaik bagi pengguna; (10) membuat karya tulis dalam bidang kepustakawanan; (11) menjadi anggota atau pengurus IPI.

Di Kemendikbud, pembinaan karir pustakawan dilakukan oleh Sub-Bagian Perpustakaan, Bagian Publikasi, Biro Komunikasi dan Layanan Masyarakat. Berdasarkan Permendikbud RI No.11 Tahun 2015 tentang Organisasi dan Tata Kerja Kemendikbud, peran dari bagian tersebut adalah mengelola jaringan perpustakaan khusus dan membina pengelola perpustakaan khusus di lingkungan Kemendikbud. Peran tersebut diwujudkan dalam kegiatan: (1) koordinasi atau diskusi panel antar-pengelola perpustakaan Kemendikbud setiap satu tahun sekali; (2) pendampingan kepada pengelola perpustakaan Kemendikbud; (3) komunikasi dengan Perpustakaan Nasional RI, IPI, dan Forum Perpustakaan Khusus untuk pengembangan jabatan fungsional pustakawan dan pengelola perpustakaan Kemendikbud; (4) workshop dalam pengenalan dan pengembangan otomasi perpustakaan. Nashihuddin (2015) mengatakan pembinaan karir calon pustakawan dan pustakawan perlu dilakukan secara berkelanjutan dengan tujuan untuk: (1) mendayagunakan kemampuan profesional pustakawan; (2) mengoptimalkan pemanfaatan sumber daya manusia berdasarkan kompetensinya dan visi misi lembaga; (3) membina kemampuan, kecakapan, keterampilan secara efisen dan rasional; (4) menyedikan spesifikasi tugas, tanggung jawab, hak dan wewenang kepada pustakawan; (5) memberikan gambaran tentang jabatan, kedudukan dan jalur yang dapat dicapai pustakawan, serta persyaratan yang harus dipenuhi untuk mencapai jabatan fungsional pustakawan; (6) memberi kesempatan kepada pustakawan untuk naik jabatan sesuai ketentuan yang berlaku; (7) menjadi dasar bagi setiap kepala perpustakaan untuk mengambil kebijakan yang berkaitan dengan sistem manajemen; (8) menciptakan keterpaduan yang serasi antara kemampuan, keterampilan, dan motivasi dengan jenjang penugasan pustakawan. 


\section{KESIMPULAN}

Berdasarkan hasil dan pembahasan di atas terlihat bahwa data responden pengelola perpustakaan Kemendikbud berjumlah 136 orang, yang terdiri dari jabatan fungsional pustakawan ahli dan terampil (21 orang atau 15,44\%); jabatan fungsional lain (113 orang atau $83,09 \%$ ); dan jabatan struktural (2 orang atau 1,47\%). Komposisi pengelola perpustakaan Kemendikbud yang terdiri dari Kepala Perpustakaan : Pustakawan : Tenaga Teknis adalah 2 : 21 : 113, yang berarti bahwa belum sesuai dengan standar pengelola perpustakaan khusus yang ditetapkan oleh Perpusnas RI. Sedangkan komposisi pustakawan ahli, pustakawan terampil, dan tenaga teknis perpustakaan Kemendikbud adalah $18: 3: 113$, yang berarti bahwa komposisi tenaga perpustakaan juga belum ideal. Seharusnya sesuai dengan standar komposisi pustakawan di perpustakaan khusus yang ditetapkan oleh Perpusnas RI, yaitu $1: 2: 4$.

Menurut kelompok usia, pustakawan Kemendikbud didominasi oleh kelompok usia 46-50 tahun $(28,57 \%)$; usia $51-55$ tahun $(19,05 \%)$; usia $56-60$ tahun $(19,05 \%)$; usia $36-40$ tahun (14,29\%); usia 25-30 tahun (9,52\%); dan usia 41-45 tahun (9,52\%). Menurut pendidikan, pustakawan Kemendikbud sebagian besar berpendidikan S1 $(71,42 \%)$; S2 dan D3 (masingmasing 14,29\%). Menurut bidang ilmu, pustakawan Kemendikbud sebagian besar berasal dari Ilmu Perpustakaan (61,90\%); Pendidikan (19,05\%); Sastra (14,29\%); dan Administrasi Negara (4,76\%). Penelitian ini diharapkan dapat memberikan saran dan masukan kepada pemangku kepentingan pengembangan pustakawan di Kemendikbud, yakni agar segera melakukan pengembangan dan pembinaan karir bagi para pengelola perpustakaan dan membuat kebijakan tentang peta jabatan pustakawan (ahli dan terampil) pada setiap satuan kerja di lingkungan Kemendikbud. 


\section{DAFTAR PUSTAKA}

Ali, A. 2006. Conducting Research in Education and the Social Science. Enugu: Tshiwa Net Woness Ltd.

Masiani, Ketut. 2015. Mempertahankan Keberadaan Perpustakaan Khusus dalam Globalisasi Informasi. Jurnal Pari 1 (1): 37-4.

Murphy, Marcy. 1991. In Future Competencies on the Information Professional, V-VI. Washington DC: Special Libraries Association.

Nashihuddin, Wahid \& Dwi R.A. 2015. Strategi Peningkatan Kompetensi dan Profesionalisme Pustakawan di Perpustakaan Khusus. Jurnal Perpustakaan Pertanian, 24 (2 Oktober): 51-58. doi:http://dx.doi.org/10.21082/jpp.v24n2.2015.p51-58.

Ratna, Nyoman Kutha. 2010. Metode Penelitian Kajian Budaya dan Ilmu Sosial Humaniora pada Umumnya. Yogyakarta: Pustaka Pelajar.

Ria, A. 2017. Perpustakaan Khusus di Indonesia. Di http://basipda.bekasikab.go.id/beritaperpustakaan-khusus-di-indonesia.html. (akses 6 Agustus 2018).

Rufaidah, Vivit Wardah. 2009. Kompetensi Pustakawan Perpustakaan Khusus (Studi Kasus Pusat Perpustakaan dan Penyebaran Teknologi Pertanian Bogor). Jurnal Perpustakaan Pertanian, 18 (1): 7-14.

Saputro, Bayu Indra. 2012. Perkembangan dan Peran Perpustakaan Khusus Balai Arkeologi Yogyakarta Sebagai Pendukung Penelitian Arkeologi. PAPUA, IV (1): 73-87.

Sugiyono. 2009. Metode Penelitian Kuantitatif Kualitatif dan R\&D. Bandung: Alfabeta.

Sulistyo-Basuki. 1991. Pengantar Ilmu Perpustakaan. Jakarta: PT. Gramedia Pustaka Utama.

Sulistyowati, E.Y. 2012. Peranan Pustakawan dalam Membentuk Citra Perpustakaan. Info Persadha 10 (2): 89-98.

Surachman, Arif. 2005. Pengelolaan Perpustakaan Khusus. Seminar Jurusan Seni Kriya, 1-7. Yogyakarta: Perpustakaan Pusat Studi Keamanan dan Perdamaian UGM.

Suwarno, Wiji. 2009. Psikologi Perpustakaan. Jakarta: Sagung Seto.

Totterdell, Anne \& Harrison, Colin T. 2000. The Library and Information Work Primer. London: Library Association Publishing.

Winarko, Bambang. 2017. Membangun Profesionallisme Pustakawan Abad ke-21. Jurnal Perpustakaan Pertanian, 26 (1 Juni): 39-45. doi:10.21082/jpp.v26n1.2017.p39-45. 